\title{
When a Trauma Becomes a Key to Identity: Enhanced Integration of Trauma Memories Predicts Posttraumatic Stress Disorder Symptoms
}

\author{
DORTHE BERNTSEN ${ }^{1 *}$ and DAVID C. RUBIN ${ }^{2}$ \\ ${ }^{1}$ University of Aarhus, Denmark \\ ${ }^{2}$ Duke University, USA
}

\begin{abstract}
SUMMARY
The Centrality of Event Scale (CES) measures the extent to which a traumatic memory forms a central component of personal identity, a turning point in the life story and a reference point for everyday inferences. In two studies, we show that the CES is positively correlated with severity of PTSD symptoms, even when controlling for measures of anxiety, depression, dissociation and selfconsciousness. The findings contradict the widespread view that poor integration of the traumatic memory into one's life story is a main cause of PTSD symptoms. Instead, enhanced integration appears to be a key issue. Copyright (C) 2006 John Wiley \& Sons, Ltd.
\end{abstract}

\section{INTRODUCTION}

Some years ago, one of us had a conversation with a student who had been involved in a severe traffic accident. The memory of this traumatic event was still bothering her very much. She explained that through the aid of her therapist, she had come to understand how the lack of control that she had experienced during the accident was not just a characteristic of this terrible event. It was in fact was an overarching theme of her whole life, including a theme of her relationship to other people. This conversation made us wonder whether it was adaptive to make an isolated, random and highly negative event so central to one's life story and identity?

Many theories of how traumatic events affect memory and self-knowledge take their starting point in the idea that a trauma creates a profound imbalance in the mind of the victim. According to this widespread view, the trauma violates the schemata of the person, is therefore hard to process and as a result becomes poorly integrated into the self-narratives of the person (e.g. Ehlers \& Clark, 2000; Horowitz, 1986; van der Kolk \& Fisler, 1995; for a review, see Dalgleish, 2004). In order to recover, the person has to accommodate his or her schemata to encompass the memory of the trauma.

Recently, we presented a different view (Berntsen \& Rubin, 2006a). We agree that a traumatic event is an unusual, unexpected and extremely emotional event that is most likely to violate our schema-driven expectations. However, deviations from schemata need not 8000 Aarhus C., Denmark. E-mail: dorthe@psy.au.dk 
lead to poor or fragmented memories (Schank, 1982, 1999). Though often overlooked in the trauma literature, deviation from schemata may enhance memory (Brewer \& Treyens, 1981; Brown \& Kulik, 1977; Hunt \& McDaniel, 1993; Rubin \& Kozin, 1984). Rather than becoming poorly integrated, we have argued that the traumatic memory-because of its distinctiveness and emotional impact — in most cases stays highly accessible and may form a cognitive reference point for the organization of autobiographical knowledge with a continuous impact on the interpretation of non-traumatic experiences and expectations for the future. We have introduced the Centrality of Event Scale (CES) measuring the extent to which a traumatic memory forms such a reference point (Berntsen \& Rubin, 2006a). The full CES consists of 20 items rated on 5-point scales $(1=$ totally disagree; $5=$ totally agree $)$ in relation to the most stressful or traumatic event in the person's life. To give the reader a sense of the CES, consider the following seven items that make up its shorter version: (1) I feel that this event has become part of my identity. (2) This event has become a reference point for the way I understand myself and the world. (3) I feel that this event has become a central part of my life story. (4) This event has coloured the way I think and feel about other experiences. (5) This event permanently changed my life. (6) I often think about the effects this event will have on my future. (7) This event was a turning point in my life.

We have shown that the CES score is positively related to symptoms of posttraumatic stress disorder (PTSD) (Berntsen \& Rubin, 2006a). Here we expand the theoretical rationale for the CES and examine its relation to other possible predictors of PTSDnotably, measures of dissociation, depression, anxiety and self-consciousness.

\section{THE THEORETICAL BACKGROUND FOR THE CENTRALITY OF EVENT SCALE}

The rationale underlying the CES takes its starting point in the fact that distinctive and emotional events usually are highly accessible and vividly remembered compared to more mundane experiences (Hunt \& McDaniel, 1993; McGaugh, 2003). Highly accessible personal memories are generally assumed to become reference points for the organization of memories of less important events. For example, they structure our life narratives by providing turning points and forming beginnings and ends of life time periods (e.g. Conway \& Pleydell-Pearce, 2000; McAdams, 2001; Robinson, 1992) and they are observed to anchor and stabilize our conceptions of ourselves (Pillemer, 1998). This literature has primarily dealt with positive memories and/or memories of cultural normative events (such as an important career choice or birth of first child). However, according to the rationale underlying the CES, memories of traumas may also form reference points for the organization of other less significant experiences. If they do, this is likely to have harmful effects on the person's well being. Rather than poor integration of an event being the problem, an enhanced integration in which the memory of the negative event is central is seen as the problem. In such cases, events that would otherwise be perceived as positive or neutral are most likely to become associated with the negative emotionality of the trauma. Ruminations, unnecessary worries and increased levels of intrusions and avoidance are likely outcomes.

The CES measures three overlapping and mutually dependent functions of such highly accessible personal memories: the extent to which the trauma memory becomes (1) a reference point for everyday inferences, (2) a turning point in the life story and (3) a central 
component of personal identity. These are three different ways in which a memory of a traumatic or stressful event may become highly interconnected with other memories and other types of autobiographical information in the cognitive networks of the person. The three functions are not independent factors of the scale. The scale has only one underlying factor (Berntsen \& Rubin, 2006a). All three functions are derived from the literature of autobiographical memory and availability heuristics (see Berntsen \& Rubin, 2006a). We will clarify these three functions in the following and explain how they may relate to symptoms of PTSD.

\section{Reference points for everyday inferences}

According to the availability heuristic (Tversky \& Kahneman, 1973), we judge the frequency and probability of specific classes of events by the ease with which we are able to retrieve them. Because frequent events are generally highly accessible, this heuristic normally works well. However, frequency is not the only factor that forms highly accessible memories. Events that are rare, surprising and intensely emotional also lead to highly accessible memories (Brown \& Kulik, 1977; Rubin \& Kozin, 1984). Personal traumas or other stressful experiences are such rare, surprising and intense events. Following the availability heuristics, because of the extraordinary accessibility of the traumatic memory, a person with a trauma is likely to overestimate the general frequency of such disturbing events as well as the likelihood of such events happening to him or her again in the future. In such cases, the traumatic memory becomes what Pillemer (1998) labels anchoring events and describes as 'a lasting reminder of the way things are' (p. 74). Possible outcomes are intrusions, unnecessary worries and precautions. In other words, having a memory of stressful event as a personal reference point is likely to generate what Ehlers and Clark (2000, p. 320) called a 'sense of serious current threat', which they considered to be an indispensable characteristic of PTSD. Moreover, having a vivid and detailed trauma memory as a central personal reference point for the interpretation of other events may also lead to over-inclusive judgements of similarity, so that a neutral current situation is perceived as similar to the traumatic event due to an accidental overlap between the two situations with respect to peripheral sensory details. The outcome may be perceptions of threat and startle responses in objectively safe situations. Thus, the high availability of a traumatic memory and its use as a personal reference point for everyday inferences and heuristic may lead to the three symptom classes of PTSD: intrusions, avoidance and arousal (American Psychiatric Association, 1994).

\section{Turning points in life stories}

According to Pillemer (1998), a turning point in a life story is 'a specific episode or series of episodes, (that) appears to alter or redirect the ongoing flow of the life course' (p. 76). Following this definition, a turning point acts as a causal agent in the life story. It provides some explanations of the subsequent choices, acts and values of the person. It can be seen as the end of one chapter of the life story and the beginning of another (Pillemer, 1998; also see McAdams, 2001). Many scholars have described how vivid and distinctive personal memories form turning points or landmarks in the life story of the person (e.g. Baerger \& McAdams, 1999; McAdams, 2001; Pillemer, 1998, 2003; Robinson, 1992; Robinson \& Taylor, 1998; Shum, 1998; Thomsen \& Berntsen, 2005). 
As pointed out by anthropologists and sociologists, turning points in a typical life course consist of culturally expected transitional events (such as choice of career, first job, marriage, birth of first child) that are anticipated to happen in a certain order and within circumscribed age spans in the life course of the individual (e.g. Neugarten, Moore, \& Lowe, 1965). Recently, we showed that such culturally shared representations of the life course (which we called life scripts) are biased towards positive events, notably positive events expected to happen in young adulthood (Berntsen \& Rubin, 2004). When we asked undergraduates to generate seven events that were most likely to happen in a prototypical life course, few negative events were recorded and disagreement was observed in the expected timing of the negative events. In contrast, many positive events were mentioned and participants showed high levels of agreement with respect to their content and their expected timing. In short, traumas and other highly negative events are generally unexpected. Thus, having a traumatic event as a salient turning point in a personal life story is likely to violate shared cultural norms as to the typical content of a life story. Such violations may be used as idioms of distress (Luborsky, 1993) and have been shown to be negatively associated with mental well being (Luborsky, 1993; Rubin \& Berntsen, 2004).

Moreover, to have a trauma as a salient turning point may lead to what McAdams (2001) labelled as contamination in the sense that positive events experienced prior to the trauma may be reinterpreted and associated with the negative emotions of the trauma. By causing the person to focus on those aspects of his or her current life conditions that can be explained by reference to the trauma and to ignore aspects that defy such causal attributions, it may cause a reduction in the multiplicity of meaning that normally characterizes our life stories (Linde, 1993; Robinson, 1996) and make the person overly preoccupied with the trauma.

\section{Components of personal identity}

The way we compose our life stories is closely related to our self-understanding and identity, according to many theorists. For example, Fitzgerald (1988) described a life story as a 'set of stories that defines who we are in narrative rather than declarative terms' ( $\mathrm{p}$. 269). McAdams (2001) similarly argues that identity 'takes the form of a story' (p. 101). Thus, if a trauma memory is seen as a central turning point in our life story it would also most likely be regarded as a central component of our personal identity.

In addition to events, our personal identity (or self-schema) includes knowledge of our social roles (Brewer, 1996; Brown, 1965) - for example the role of a teacher, a parent and a spouse. This identity component can also be related to our life story in that many culturally expected turning points in life deal with the transition from one social role to another, such as from single to married (Berntsen \& Rubin, 2004; Neugarten et al., 1965). Thus, to the extent our life story matches the life script of our culture (as described above, cf. Berntsen \& Rubin, 2004), it will include such culturally sanctioned role transitions and thereby support our personal identification with the social roles that are culturally expected. On the other hand, if a trauma memory becomes a central turning point in our life story, the social role of being a trauma victim, or trauma survivor, is likely to become similarly salient in our conception of ourselves, and thus an important component of personal identity. The result may be that the person who has adopted the social role of a trauma victim finds it harder to relate to people who associate themselves with more traditional social roles. Since the latter forms the majority of most populations, the outcome may be an experience of social isolation and stigmatization. 
Furthermore, having a traumatic event as central to personal identity is likely to mean that the trauma is seen as a symbol for persistent themes in the person's life story, as in the example we offered in the beginning. This may lead to what Abramson and Seligman (1978) called internal, stable and global attributions: The trauma is seen as causally related to stable characteristics of the self that pertain across situations. This attributional style is positively related to depression (Peterson \& Seligman, 1984) and to PTSD symptoms (Greening, Stoppelbein, \& Docter, 2002).

\section{PRIOR STUDIES ON THE CENTRALITY OF EVENT SCALE}

Berntsen and Rubin (2006a) tested the 20-item CES and a shorter 7-item CES on a sample of 707 undergraduates drawn from four Universities in the USA: Duke University, North Carolina State University, Wayne State University and University of North Dakota. Based on this sample, the scales were reliable ( $\alpha$ 's of 0.94 and 0.88 , respectively), had one underlying factor and were unaffected by whether the stressful event would be classified as a trauma under the A1 criteria of the DSM-IV. In a subsample of 224 Duke University undergraduates, the 20 -item scale correlated 0.38 with a measure of PTSD symptoms and 0.23 with the Beck Depression Inventory. Several earlier studies leading to the CES also demonstrated the unity and usefulness of the scale (e.g. Berntsen, Willert, \& Rubin, 2003). In a study involving 111 Danish undergraduates (Rubin \& Berntsen, 2004), five items of the CES produced a reliable scale $(\alpha=0.91)$ which correlated positively $(r=0.45)$ with the PTSD checklist (PCL; Blanchard, Jones-Alexander, Buckley, \& Foneris, 1996; Weathers, Litz, Huska, \& Keane, 1994), and also showed a positive correlation $(r=0.36)$ with the Beck Depression Inventory II (BDI-II, Beck, Ward, Mendelson, Mock, \& Erbaugh, 1961). In a study of older adults reporting on stressful events from the Danish occupation during World War II (Berntsen \& Thomsen, 2005), three of the CES items formed a scale with an $\alpha$ of 0.77 which correlated with the participants' estimates of the frequency of intrusive memories $(r=0.37)$ and dreams $(r=0.35)$ referring to the time of the occupation and with the extent to which participants agreed that the war had left a scar on their soul $(r=0.57)$. In a study using Gallup interviews in Denmark, three CES items were included that had the highest correlations with the rest of the test in Berntsen and Rubin (2006a), as well as four items to measure PTSD symptoms (Berntsen \& Rubin, 2006b). The 423 Danes who were old enough to be alive during World War II answered with respect to the occupation of Denmark. Their three CES items produced a reliable scale $(\alpha=0.84)$ which correlated with the four-item PTSD symptoms scale $(r=0.51)$. The 836 younger Danes answered with respect to an emotionally negative event over the age of eight. Their three CES items were reliable $(\alpha=0.80)$ and correlated with the four-item PTSD symptoms scale $(r=0.44)$. Finally, questions adapted from the CES correlated positively with a sum score for memory clarity in a study of flashbulb memories for the fall of the Berlin Wall (Bohn \& Berntsen, in press).

Here we examine the relation between the CES and other possible predictors of PTSD symptoms. The aim is to examine whether the CES is an independent predictor of PTSD symptoms once such other factors have been controlled. We include measures of dissociation, because high levels of dissociation have been found to predict PTSD symptoms (Bernstein \& Putman, 1986). We include measures of anxiety, because PTSD is classified as an anxiety disorder (American Psychiatric Association, 1994). Measures of depression are included because of the high comorbidity between PTSD and depression 
(Kessler, Sonnega, Bromet, Hughes, \& Nelson, 1995). We also include a measure of absorption because of its relation to dissociation and autobiographical memory (Clancy, McNally, Pitman, Schacter, \& Lenzenweger, 2002). We include a measure of selfconsciousness, because the CES can be seen to measure certain types of self-focusing thought.

\section{STUDY 1}

\section{Method}

\section{Participants}

Two hundred and forty-seven Danish psychology majors participated (201 females; mean age $=26.8$, range $20-60$ ).

\section{Material}

We included the 20-item CES (Berntsen \& Rubin, 2006a), the Posttraumatic Stress Disorder Checklist (PCL; Blanchard et al., 1996; Weathers et al., 1994), the Dissociative Experience Scale (DES; Bernstein \& Putman, 1986), the BDI-II (Beck et al., 1961), the State-Trait Anxiety Inventory (STAI; Gaudry, Vagg, \& Spielberger, 1975; Spielberger, Gorsuch, \& Lushene, 1970) and the Tellegen Absorption Scale (TAS, Tellegen \& Atkinson, 1974; Zachariae, Jørgensen, Bjerring, \& Svendsen, 2000).

\section{Procedure}

The participants answered the questionnaires as part of a course. All questionnaires were administered in groups. All 247 participants were given the CES, PCL and DES. Of these 247 students, 129 were also given the STAI (i.e. STAI-S and STAI-T to measure state and trait anxiety, respectively), and the remaining 118 participants were given the BDI and the TAS. In answering the CES, the participants were asked to think back upon the most stressful or traumatic event in their life and then answer the questions in an honest and sincere way (cf. Berntsen \& Rubin, 2006a). For the PCL, the participants were asked to consider a list of 17 symptoms that make up the official PTSD diagnosis from the DSM IV (American Psychiatric Association, 1994) as they apply to a stressful life experience and to indicate on rating scales how much they had been bothered by these problems in the past month (cf. Blanchard et al., 1996; Weathers et al., 1994). The participants answered the questionnaires at their own pace. They were ensured that their answers were anonymous and would be treated confidentially.

\section{Results}

Data from the 247 participants who answered the PCL, CES and DES showed significant correlations with the PCL for both the CES $(r(234)=0.39, p<0.0001)$ and the DES $(r(234)=0.26, p<0.0001)$, whereas the CES and the DES did not correlate with one another $(r(234)=0.09, p>0.1)$. A multiple regression analysis with the PCL score as the dependent variable, and the CES and DES as predictor variables showed that both predictor variables were independently associated with the PCL score, with the CES showing a higher beta coefficient $(\beta=0.37, t=6.33, p<0.0001)$ compared to the DES $(\beta=0.22$, $t=3.81, p<0.001)$. 
Table 1. Correlations among tests for Danish undergraduates $(N=123)$

\begin{tabular}{lllll}
\hline & PCL & CES & DES & STAI-S \\
\hline CES & $0.38^{* * *}$ & & & \\
DES & $0.22^{*}$ & 0.10 & & \\
STAI-S & $0.49^{* * *}$ & $0.32^{* *}$ & 0.11 & \\
STAI-T & $0.63^{* * *}$ & $0.36^{* * *}$ & $0.25^{* *}$ & $0.56^{* * *}$ \\
\hline${ }^{*} p<0.05$. & & & \\
${ }^{* * *} p<0.01$. & & & & \\
${ }^{* * * *} p<0.0001$. & & & &
\end{tabular}

The same analyses were conducted for those 129 participants who were given the STAI$\mathrm{T}$ and the STAI-S in addition to the CES, PCL and DES. The correlations are shown in Table 1. All four independent variables correlated positively with the PCL score, with measures of state anxiety (STAI-S) and trait anxiety (STAI-T) showing the highest correlations. In addition, STAI-T and STAI-S also showed moderate correlations with the CES. A multiple regression analysis with the PCL score as the dependent variable and the CES, DES, STAI-S and STAI-T as predictor variables showed a significant effect for the CES $(\beta=0.15, t=2.08, p<0.05)$ though the best predictor was the STAI-T $(\beta=0.45$, $t=5.19, p<0.0001)$. The STAI-S was also a significant predictor $(\beta=0.18, t=2.10$, $p<0.05)$, whereas no significant effect was found for the DES $(p>0.3)$.

Table 2 shows the correlations for those 118 participants who were given the BDI and the TAS in addition to the PCL, CES and DES. Again, all the included measures were found to correlate positively with the PCL, with the BDI showing the highest correlation. Consistent with our previous work (Berntsen \& Rubin, 2006a), the BDI also correlated positively with the CES. A multiple regression analysis with the PCL score as the dependent variable and the CES, DES, BDI and TAS as predictor variables again showed a significant effect for the CES $(\beta=0.14, t=2.03, p<0.05)$ though the best predictor was the BDI $(\beta=0.68$, $t=8.77, p<0.0001)$. The TAS also entered as a significant predictor $(\beta=0.18, t=2.55$, $p<0.05)$, whereas no significant effect was found for the DES $(p>0.5)$.

\section{Discussion}

The results established that the CES is independently related to PTSD symptoms. The CES correlated positively with measures of state/trait anxiety and depression, but showed a reliable association with PTSD symptoms independent of its correlation with these measures. The measures of anxiety and depression greatly reduced the contribution of the

Table 2. Correlations among tests for Danish undergraduates $(N=111)$

\begin{tabular}{llllr}
\hline & PCL & CES & DES & BDI \\
\hline CES & $0.43^{* * *}$ & & & \\
DES & $0.30^{* *}$ & 0.04 & & \\
BDI & $0.72^{* * *}$ & $0.39^{* * *}$ & $0.40^{* * *}$ & 0.07 \\
TAS & $0.22^{*}$ & 0.11 & $0.39^{* * *}$ & 0.07 \\
\hline
\end{tabular}

${ }^{*} p<0.05$.

${ }^{* *} p<0.01$.

${ }^{* * *} p<0.0001$. 
CES in predicting PTSD symptoms. This may be because the CES, and measures of anxiety or depression all contribute as predictors in the usual sense. However, from a theoretical perspective, PTSD is an anxiety disorder with a high comorbidity with depression and when measures of depression or anxiety are used as predictors they can be seen as removing aspects of what is conceptually central to PTSD.

One limitation of Study 1 is that it is not clear how many of the participants answered the CES and the PCL with reference to a stressful or traumatic event that satisfies the A1 and A2 criteria for a traumatic event, according to the DSM-IV (American Psychiatric Association, 1994). To clarify this issue, Study 2 includes questions regarding characteristics of the stressful or traumatic event. This will allow us to examine whether the relation between the CES and the PCL differs between participants with and without a traumatic event that satisfies the A1 and A2 trauma criteria. To fulfil the A1 criterion, the person should have experienced, witnessed or been confronted with an event that involved actual or threatened death or serious injury, or a threat to the physical integrity of him- or herself or others. To fulfil the A2 criterion, the person should have responded to the trauma with intense fear, helplessness or horror.

\section{STUDY 2}

According to results from Study 1, an important factor for the development and maintenance of PTSD symptoms is the extent to which a highly emotionally negative event has become a personal reference point for the attribution of meaning to other events, a salient turning point in the life story and a central component of a person's identity and selfunderstanding. This suggests that the role of the traumatic memory in the overall cognitive organization of personal memories related to life story and identity may be critical for the development and/or maintenance of PTSD symptoms. One important consequence of this view is that PTSD symptoms may arise in response to stressful, negative events that do not fulfil the formal diagnostic criteria for a trauma according the DSM-IV (American Psychiatric Association, 1994) provided that the memory in question has become sufficiently central for the person's understanding of him- or herself and the world. As a consequence, PTSD symptoms may occur in response to events involving a wide range of emotions, not just fear, horror and helplessness, contrary to what is indicated by the diagnostic criteria (American Psychiatric Association, 1994) provided that the memories for the events in question are emotionally negative and have become central to the person in the ways described above. One aim of Study 2 is to examine this question.

As noted by Berntsen and Rubin (2006a), it is not clear whether the severity of PTSD symptoms increases linearly with CES. A second aim of Study 2 is the therefore to clarify the functional shape of the relation between the CES and PTSD symptoms. A third aim of Study 2 is to explore the relation between the CES and measures of self-consciousness in relation to symptoms of PTSD.

\section{Method}

\section{Participants}

Four hundred and forty-two Duke undergraduates participated as part of a requirement for introductory courses (249 females; mean age $=17.8$, range 16-23). 


\section{Material}

We used the following tests which were identical to those used in translation in Study 1: the PCL (Blanchard et al., 1996; Weathers et al., 1994), the DES (Bernstein \& Putman, 1986), and the BDI-II (Beck et al., 1961). We used the 7-item CES to provide a test of it independent of the 20-item version (CES; Berntsen \& Rubin, 2006a), and we added the Self-Consciousness Scale (SCS; Fenigstein, Scheier, \& Buss, 1973). At the end of the CES, we asked participants to categorize their dominant emotion as either anger, disgust, fear, guilt, sadness, shame or shock. We also asked them to indicate whether 'In the most stressful or traumatic event that you used to answer questions 1-7, did you experience, witness or were you confronted with an event that involved actual or threatened death or serious injury, or threat to your physical integrity or that of others?' and 'Did you response involve intense fear, helplessness or horror?' These last two questions address whether the participants had an A1 criterion trauma and whether they had an A2 criterion emotional reaction to it according to the DSM IV, respectively. If they answered yes to both, we considered that they had a trauma according the DSM IV criterion (American Psychiatric Association, 1994).

\section{Procedure}

The instructions were similar to the ones used in Study 1. All questionnaires were administered in groups. All 442 participants were given the CES, PCL and BDI. Of these approximately half were also given the DES and the SCS. The participants answered the questionnaires at their own pace. They were ensured that their answers were anonymous and would be treated confidentially.

\section{Results}

Thirty-eight per cent of the participants indicated that their most stressful event satisfied the A1 stressor criterion of the DSM-IV, and 50\% confirmed the A2 criterion. Twenty-seven per cent answered yes to both the A1 and A2 trauma questions and thus indicated that they had a trauma satisfying the official diagnostic criteria. The means of both the CES and the PCL were higher in this group (the DSM-trauma group in the following) than among participants who did not fulfil both of the official A trauma criteria. For the PCL, the means (and standard deviations) were 34.88 (12.68) versus 30.37 (11.30) in the DSM-trauma group versus others, respectively $(F(1,394)=11.50, p<0.001)$. For the CES, the means (and standard deviations) were 3.56 (1.07) versus 3.09 (1.10) in the DSM-trauma group versus others, respectively ( $F(1$, $424)=15.33, p<0.001)$. Interestingly, in spite of these differences, the correlation between the CES and PCL was similar in the two groups, namely $r=0.32(N=105, p<0.001)$ in the DSMtrauma group versus $r=0.34(N=288, p<0.0001)$ in the non DSM-trauma group. The relation between our two central variables remains constant across the two groups, allowing us to collapse the data from these two groups.

Correlations among the tests are shown in Table 3. All four independent variables correlated positively with the PCL score, with measures of self-consciousness (SCS) showing lower correlations. In addition, PCL and BDI showed moderate correlations with the CES.

A multiple regression analysis using the variables on which we had the most data was done with the PCL score as the dependent variable and the CES and BDI as predictor variables. With 371 participants providing data for all three scales, both predictor variables were independently associated with the PCL score, with the BDI showing a higher beta coefficient $(\beta=0.42, t=9.29, p<0.0001)$ compared to the CES $(\beta=0.25, t=5.50$, 
Table 3. Correlations (with number of observations) among tests for Duke undergraduates

\begin{tabular}{lcccc}
\hline & PCL & CES & BDI & DES \\
\hline CES & $0.35(395)^{* * *}$ & & & \\
BDI & $0.48(382)^{* * *}$ & $0.27(401)^{* * *}$ & & \\
DES & $0.45(182)^{* * *}$ & $0.18(200)^{*}$ & $0.42(191)^{* *}$ & \\
SCS & $0.28(191)^{* * *}$ & $0.21(209)^{* *}$ & $0.21(198)^{* *}$ & $0.22(201)^{* *}$ \\
${ }^{*} p<0.05$. & & & & \\
$* * p<0.01$. & & & & \\
${ }^{* * *} p<0.0001$. & & & & \\
& & & &
\end{tabular}

$p<0.0001)$. The regression analysis was repeated for those participants who were also given the DES and SCS in addition to the PCL, CES and BDI. With 167 participants providing data for all five scales, it showed significant effects for the BDI $(\beta=0.21$, $t=2.97, p<0.01)$, CES $(\beta=0.22, t=3.35, p<0.001)$ and DES $(\beta=0.33, t=4.59$, $p<0.0001$ ), but no significant effect for the SCS which would have entered at $p=0.09$.

The number of participants endorsing each of our seven categories of dominant emotions for their most stressful or traumatic event was as follows: anger, 64; disgust, 10; fear, 57; guilt, 29; sadness, 134; shame, 30 and shock, 40. Thus, fear and shock, the two emotions expected by the diagnosis of PTSD were not the most frequent. We then asked whether the PCL or CES differed by emotion. We removed disgust because of its low frequency of response. The remaining six emotions did not cause significant difference in the PCL $(F(5,323)=0.99, p=0.43)$ or the CES $(F(5,344)=1.24, p=0.29)$. From the description of PTSD in the DSM-IV (American Psychiatric Association, 1994), one might have expected fear and shock to be related to significantly higher PTSD symptoms, but they were not; in terms of magnitude, anger had the highest PCL mean of 34, whereas fear and shock had means of 32 and 30.

Our main interest is in the relation of the centrality of stressful/traumatic events to PTSD symptoms. Including both Study 1 and Study 2, we had a total of 647 undergraduates who had filled out the PCL and either the 20- or 7-item version of the CES, the only tests taken by all participants in both studies. Using these data, we investigated the functional relationship between the PCL and CES by dividing the CES into quintiles, with cutoff values of 2.35, 3.06, 3.56 and 4.06, and plotting the PCL scores in each quintile in the top panel of Figure 1. Because a score of 44 on the PCL is a good cutoff score for predicting PTSD for people who have had a trauma (Blanchard et al., 1996), we also plotted the per cent of participants in each quintile with a PCL score over 43 in the bottom panel of Figure 1 . Because there were approximately 130 participants in each quintile, the standard error for each point plotted is quite small, averaging 0.92 for the PCL panel and for $3 \%$ for the percentage panel. The top panel of the figure shows a large and orderly effect of the CES, with a monotonic and fairly linear increase in the PCL from near its minimum value of 17. The bottom panel of the figure shows that the CES has minimal effects on the percentage of participants with PCL scores over 43 until it reaches its midscale value of 3, but then has notable increases beyond that.

\section{GENERAL DISCUSSION}

Many theories of PTSD hold as a basic assumption that a traumatic event violates schematized knowledge, which in turn leads to poor processing of the traumatic event and 

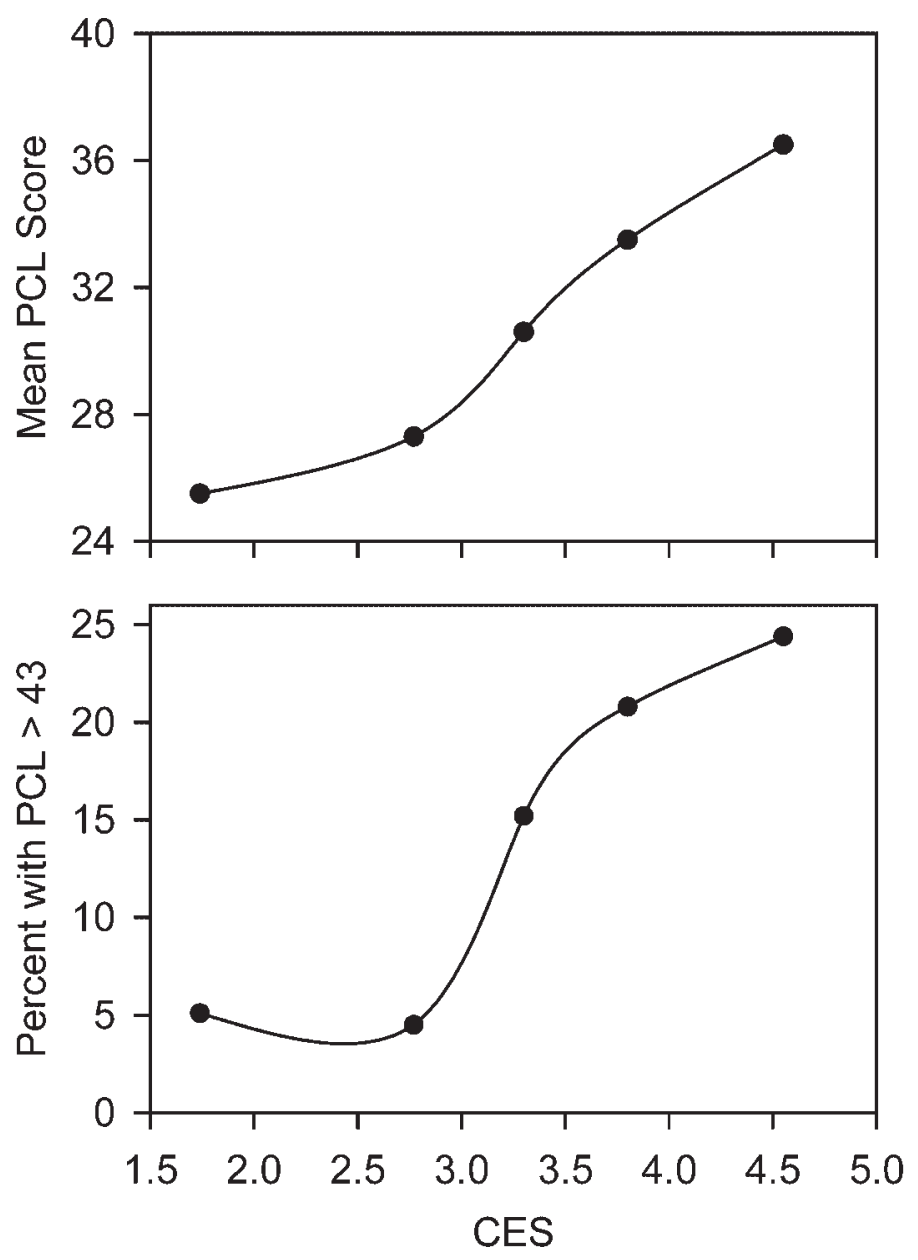

Figure 1. The top panel shows the functional relation between the PCL test of PTSD symptoms and the CES, which was divided into quintiles, using data from Study 1 and Study 2 combined. The bottom panel shows the percentage of participants in each CES quintile with PCL scores above 43, an estimate of the cutoff for a diagnosis of PTSD

an ensuing incomplete integration of the traumatic event in the person's knowledge of himor herself and the world. Though this thesis is probably most clearly presented in Horowitz's (1986) seminal work, it can be found in many subsequent theoretical developments of PTSD as well (e.g. Brewin, Dalgleish, \& Joseph, 1996; Ehlers \& Clark, 2000; Foa \& Riggs, 1993; van der Kolk \& Fisler, 1995; for a review, see Dalgleish, 2004). The findings presented here and in our previous work (e.g. Berntsen \& Rubin, 2006a) conflict with this conventional view. Rather than being poorly integrated, we have shown that the traumatic memory tends to form a cognitive reference point for the organization of other memories and for generating expectations for the future. We have shown that the extent to which it takes this role is positively related to symptoms of PTSD, also when controlling for measures of dissociation, anxiety, depression and selfconsciousness. 
Could the incompatibility between the present findings and the disintegration view be solved by assuming that making the traumatic event overly central to your life story and identity is in fact a form of disintegration? We do not think so. Memories that score high on the CES are highly available reference points that structure the organization of other memories. These properties are opposite to the way the notion of disintegration is normally used in the PTSD literature. Most PTSD theorists have used this notion in ways that (contrary to the CES) imply reduced accessibility of the traumatic memory and difficulties in narrating coherently about the event and its role in the overall life story (see Dalgleish, 2004, for a review). Following such operationalizations of disintegration, the type of cognitive organization measured by the CES cannot be considered as disintegration but should rather be considered as the other extreme of the disintegration/integration dimension (in which individuals with high CES scores show extreme integration).

A trauma is typically a very shocking event that violates schema-driven expectations. However, deviation from schemata need not lead to impoverished memory. Instead, it often leads to enhanced memory for the schema-incongruent material. According to standard cognitive theories of schema-based processing, encountering schema-deviant material may lead to the formation of a new schema structured around the incongruent material (e.g. Schank, 1982, 1999). The theoretical rationale behind the CES is in agreement with such standard ideas in cognitive psychology. Our findings can also be seen to agree with an accumulating number of clinical studies showing the maladaptive consequences of certain forms of self-focused thought—such as rumination (Nolen-Hoeksema, 1996) and worry (Borkovec, Ray, \& Stöber, 1998). To clarify the relation between the CES and such thought processes is a task for future research.

Twenty-seven per cent of our participants in Study 2 indicated that their most stressful event satisfied the A1 and A2 trauma criteria in the DSM-IV (American Psychiatric Association, 1994). These participants had more severe PTSD symptoms and scored higher on the CES than those with other types of stressful events. However, the positive relation between the CES and PTSD symptoms was equally strong in both groups, indicating that this relation is not a product of the type or severity of the traumatic/stressful event, nor it is limited to people with only milder traumas. In addition, findings from Study 2 showed that PTSD symptoms and CES score did not vary as a function of which of seven emotions the subject had nominated as the most dominant emotion at the time of the event. Thus, fear and horror were not found to be more strongly associated with PTSD symptoms than other emotions, contrary to what is indicated in the PTSD diagnosis. Taken together, these findings suggest that some characteristics of the traumatic/stressful event (e.g. overall emotional arousal and how much the event is rehearsed in thoughts and conversations) are likely to influence how central this event subsequently becomes in memory, whereas other characteristics (e.g. the presence of certain specific emotions) do not seem to have a strong effect. Future research should clarify this issue. At the same time, the findings show that the relation between the CES and PTSD symptoms is not contingent upon type and severity of traumatic events but can be observed in relation to both milder and more severe traumatic/ stressful experiences.

Though only indirectly concerned with clinical intervention in relation to posttraumatic responses, our present and previous findings do suggest that it may be harmful to help a client with PTSD to perceive thematic connections and similarities between the traumatic event and previous experiences in this person's life. While it is true that some traumatic events are inherently turning points in that they create profound changes in a person's life, it also the case that our life stories are subject to constant reconstruction and that any 
reconstruction or retelling of the life narrative is carried out from a certain vantage point (Robinson, 1996). As noted by Robinson in relation to the construction of autobiographical meaning: 'There is the urge to judge one meaning as 'true' and others as mistakenly biased. Accuracy is the wrong category to use in such cases. Meaning should be judged by other criteria, such as authenticity and functional impact' (p. 202). Reconstructing a personal life story with the perspective of a trauma survivor, and rendering this perspective unique and superior to other possible vantage points is to render the traumatic memory highly central to the understanding of the personal past, the expected future and the current self. As we have shown here, such a strategy is maladaptive.

\section{ACKNOWLEDGEMENTS}

We wish to thank Heather Rice and Tim Strauman for providing the Self-Consciousness Scale and Beck Depression Inventory data for Study 2 and National Institute of Mental Health grant number R01 MH066079 for support.

\section{REFERENCES}

Abramson, L. Y., \& Seligman, M. E. P. (1978). Learned helplessness in humans: Critique and reformulation. Journal of Abnormal Psychology, 87, 49-74.

American Psychiatric Association. (1994). Diagnostic and statistic manual of mental disorders (4th ed.). Washington, DC: American Psychiatric Association.

Baerger, D. R., \& McAdams, D. P. (1999). Life story coherence and its relation to psychological wellbeing. Narrative Inquiry, 9, 69-96.

Beck, A. T., Ward, C. H., Mendelson, M., Mock, J., \& Erbaugh, J. (1961). An inventory for measuring depression. Archives of General Psychiatry, 4, 561-571.

Blanchard, E. B., Jones-Alexander, J., Buckley, T. C., \& Foneris, C. A. (1996). Psychometric properties of the PTSD checklist (PCL). Behaviour, Research and Therapy, 34, 669-673.

Bernstein, E. M., \& Putman, F. W. (1986). Development, reliability, and validity of a dissociation scale. The Journal of Nervous and Mental Disease, 174, 727-735.

Berntsen, D., \& Rubin, D. C. (2004). Cultural life scripts structure recall from autobiographical memory. Memory \& Cognition, 32, 427-442.

Berntsen, D., \& Rubin, D. C. (2006a). Centrality of Event Scale: A measure of integrating a trauma into one's identity and its relation to post-traumatic stress disorder symptoms. Behaviour Research and Therapy, 44, 219-231.

Berntsen, D., \& Rubin, D. C. (2006b). Flashbulb memories and posttraumatic stress reactions across the life-span: Age-related effects of the German occupation of Denmark during WWII. Psychology and Aging, 21, 127-139.

Berntsen, D., \& Thomsen, D. K. (2005). Personal memories for remote historical events. Accuracy and clarity for flashbulb memories related to WWII. Journal of Experimental Psychology: General, 134, 242-257.

Berntsen, D., Willert, M., \& Rubin, D. C. (2003). Splintered memories or vivid landmarks? Qualities and organization of traumatic memories with and without PTSD. Applied Cognitive Psychology, 17, 675-693.

Bohn, A., \& Berntsen, D. (in press). Pleasantness bias in flashbulb memories: Positive and negative flashbulb memories of the fall of the Berlin wall. Memory \& Cognition.

Borkovec, T. D., Ray, W. J., \& Stöber, J. (1998). Worry: A cognitive phenomenon intimately linked to affective, physiological, and interpersonal behavioral processes. Cognitive Therapy and Research, 22, 561-576.

Brewer, W. F. (1996). What is recollective memory? In D. C. Rubin (Ed.), Remembering our past: Studies in autobiographical memory (pp. 19-66). Cambridge UK: Cambridge University Press. 
Brewer, W. F., \& Treyens, J. C. (1981). Role of schemata in memory for places. Cognitive Psychology, 13, 207-230.

Brewin, C. R., Dalgleish, T., \& Joseph, S. (1996). A dual representation theory of posttraumatic stress disorder. Psychological Review, 103, 670-686.

Brown, R. (1965). Social psychology. New York: The Free Press.

Brown, R., \& Kulik, J. (1977). Flashbulb memories. Cognition, 5, 73-99.

Clancy, S. A., McNally, R. J., Pitman, R. K., Schacter, D. L., \& Lenzenweger, M. F. (2002). Memory distortions in people reporting abduction by aliens. Journal of Abnormal Psychology, 111, 455-461.

Conway, M. A., \& Pleydell-Pearce, C. W. (2000). The construction of autobiographical memories in the self-memory system. Psychological Review, 107, 261-288.

Dalgleish, T. (2004). Cognitive approaches to posttraumatic stress disorder: The evolution of multirepresentational theorizing. Psychological Bulletin, 130, 228-260.

Ehlers, A., \& Clark, D. M. (2000). A cognitive model of posttraumatic stress disorder. Behavior Research and Therapy, 38, 319-345.

Fenigstein, A., Scheier, M. F., \& Buss, A. H. (1973). Public and private self-consciousness: Assessment and theory. Journal of Consulting and Clinical Psychology, 4, 522-527.

Fitzgerald, J. M. (1988). Vivid memories and the reminiscence phenomenon: The role of a self narrative. Human Development, 31, 261-273.

Foa, E. B., \& Riggs, D. S. (1993). Post-traumatic stress disorder in rape victims. In J. Oldham, M. B. Riba, \& A. Tasman (Eds.), Review of psychiatry (Vol. 12, pp. 273-303). Washington, D.C: American Psychiatric Association.

Gaudry, E., Vagg, P., \& Spielberger, C. D. (1975). Validation of the state-trait distinction in anxiety research. Multivariate Behavioral Research, 10, 331-341.

Greening, L., Stoppelbein, L., \& Docter, R. (2002). The mediating effects of attributional style and eventspecific attributions on postdisaster adjustment. Cognitive Therapy and Research, 26, 261-274.

Horowitz, M.J. (1986). Stress response syndromes (2nd ed.). Northvale, NJ: Jason Aronson.

Hunt, R. R., \& McDaniel, M. A. (1993). The enigma of organization and distinctiveness. Journal of Memory and Language, 32, 421-445.

Kessler, R. C., Sonnega, A., Bromet, E., Hughes, M., \& Nelson, C. B. (1995). Posttraumatic stress disorder in the National Comormidity Survey. Archives of general Psychiatry, 52, 1048-1060.

Linde, C. (1993). Life stories: The creation of coherence. New York: Oxford University Press.

Luborsky, M. R. (1993). The romance with personal meaning in gerontology: Cultural aspects of life themes. The Gerontologist, 33, 445-452.

McAdams, D. P. (2001). The psychology of life stories. Review of General Psychology, 5, 100-122.

McGaugh, J. L. (2003). Memory and emotion: The making of lasting memories. New York: Columbia University Press.

Neugarten, B. L., Moore, J. W., \& Lowe, J. C. (1965). Age norms, age constraints, and adult socialization. The American Journal of Sociology, 70, 710-717.

Nolen-Hoeksema, S. (1996). Chewing the cud and other ruminations. In R. S. Wyer (Ed.), Advances in social cognition (pp. 135-144). Hillsdale, NJ: Erlbaum.

Peterson, C., \& Seligman, M. E. (1984). Causal explanations as a risk factor for depression: Theory and evidence. Psychological Review, 91, 347-374.

Pillemer, D. B. (1998). Momentous events, vivid memories. Cambridge: Harvard University Press.

Pillemer, D. B. (2003). Directive functions or autobiographical memory: The guiding power of the specific episode. Memory, 11, 193-202.

Robinson, J. A. (1992). First experiences: Contexts and functions in personal histories. In M. A. Conway, D. C. Rubin, H. Spinnler, \& W. Wagenaar (Eds.), Theoretical perspectives on autobiographical memory (pp. 223-239). Utrecht: Kluwer Academic Publishers.

Robinson, J. A. (1996). Perspective, meaning and remembering. In D. C. Rubin (Ed.), Remembering our past: Studies in autobiographical memory (pp. 199-217). Cambridge: Cambridge University Press.

Robinson, J. A., \& Taylor, L. R. (1998). Autobiographical memory and self-narratives: A tale of two stories. In C. P. Thompson, D. J. Herrmann, D. Bruce, J. D. Read, D. G. Payne, \& M. P. Toglia (Eds.), Autobiographical memory: Theoretical and applied perspectives (pp. 125-143). Mahwah, NJ: Lawrence Erlbaum Associates.

Rubin, D. C., \& Kozin, M. (1984). Vivid memories. Cognition, 16, 81-95. 
Rubin, D. C., \& Berntsen, D. (2004). Remembering the road less traveled makes a difference: Divergence from a life script correlates with psychological distress. Poster presented at the 10th Cognitive Aging Congress, Atlanta, April 1-4.

Tversky, A., \& Kahneman, D. (1973). Availability: A heuristic for judging frequency and probability. Cognitive Psychology, 5, 207-232.

Schank, R. C. (1982). Dynamic memory. New York: Cambridge University Press.

Schank, R.C. (1999). Dynamic memory revisited. New York: Cambridge University Press.

Shum, M. S. (1998). The role of temporal landmarks in the autobiographical memory processes. Psychological Bulletin, 124, 423-442.

Spielberger, C. D., Gorsuch, R. L., \& Lushene, R. E. (1970). Test manua for the stait-trait anxiety inventory. Palo Alto, California: Consulting Psychologists Press.

Tellegen, A., \& Atkinson, G. (1974). Openness to absorbing and self-altering experiences ("absorption"), a trait related to hypnotic susceptibility. Journal of Abnormal Psychology, 83, 268-277.

Thomsen, D. K., \& Berntsen, D. (2005). The end point effect in autobiographical memory: More than a calendar is needed. Memory, 13, 846-861

Van der Kolk, B. A., \& Fisler, R. (1995). Dissociation and the fragmentary nature of traumatic memories: Overview and exploratory study. Journal of Traumatic Stress, 8, 505-525.

Weathers, F. W., Litz, B. T., Huska, J. A., \& Keane, T. M. (1994). The PTSD checklist (PCL). Unpublished scale available from the National Center for PTSD.

Zachariae, R., Jørgensen, M. M., Bjerring, P., \& Svendsen, G. (2000). Autonomic and psychological responses to acute psychological stressor and relaxation: The influence of hypnotizability and absorption. International Journal of Clinical and Experimental Hypnosis, 48, 388-403. 